\title{
Identification and antioxidant activity of Ammi visnaga $L$. polyphenols from the Middle Atlas in Morocco
}

\author{
Jamila El Karkouri *, Aziz Drioiche, Aminata Soro, Atika Ailli, Nadia Benhlima, Amal Bouzoubaa, \\ Fadoua El Makhoukhi, Hamid Oulhaj, Ferdinand Kouoh Elombo and Touriya Zair*
}

Chemistry of bioactive molecules and environment research team, Faculty of Sciences, Po Box. 11201, Zitoune, Meknes-Morocco

\begin{abstract}
In this work, we are interested in both the study of the phenolic compounds and the evaluation of the antioxidant properties of the extracts of Ammi visnaga L. collected from the Middle Atlas in Morocco. Phytochemical screening was carried out to highlight the qualitative composition of the secondary metabolites contained in this plant. Also, the extraction of total polyphenols was carried out by maceration using hydromethanolic and hydroacetonic mixtures. Then, the fractionation of the crude extracts was conducted by liquid-liquid extraction using successively two organic solvents with different polarities: ethyl acetate and n-butanol. The polyphenols contents were spectrophotometrically estimated using the Folin-Ciocalteau method. It showed that the ethyl acetate fraction is more abundant in phenolic compounds than the other fractions. The qualitative analysis was performed by high-pressure liquid chromatography with U.V. and electrospray ionization coupled to mass spectrometry (HPLC/UV-ESI-MS), which confirmed the richness of this species in polyphenols and particularly in flavonoids, especially by the identification of kaempferol, rhamnetin, biochanin A, ammiol. These molecules belong to flavones, flavonols, and furochromones, which are also identified both in the form of genin and of heteroside. The antioxidant activity of the different fractions was evaluated by diphenyl-picrylhydrazyl (DPPH•). The $\mathrm{IC}_{50}$ is equal to $12.87 \mu \mathrm{g} / \mathrm{mL}$ for the ethyl acetate fraction, against $8.8 \mu \mathrm{g} / \mathrm{mL}$ for ascorbic acid and $10.8 \mu \mathrm{g} / \mathrm{mL}$ for BHA which are used as reference compounds.
\end{abstract}

Keywords: Ammi visnaga L.; phytochemical screening; polyphenols; antioxidant activity; HPLC/UV-ESI-MS.

\section{Introduction}

Aromatic and medicinal plants are a great source of the majority of natural antioxidants. However, they are still underexploited in the medical field, in the pharmaceutical, and the food industry. Indeed, the oxidation of lipids in food induces not only a loss of its nutritional value but also some harmful effects on the consumer's health, which can lead to a lot of diseases ${ }^{1}$. The presence of antioxidants in food has become mandatory for both this quality and its safety. Food, cosmetic, and pharmaceutical industries face real problems due to the use of synthetic antioxidants. So, natural antioxidants are recommended to replace synthetic antioxidants to minimize this damage.

Ammi visnaga L. (khella) is a wild herb (aromatic and medicinal) of the Apiaceae (Umbelliferae) family, and it is widely distributed in the Mediterranean, South and North America, India, Russia, Europe, Southwest Asia, Argentina, Chile, Mexico, the Atlantic and Iraq ${ }^{2,3}$. It is an annual or bi-annual plant of 20 to 100 centimeters high ${ }^{4,5}$. It is also called bishop herb ${ }^{6}$. Its fruits are in the form of smooth ovoid diakenes ${ }^{7,8}$. Both its umbels and fruits are known for their virtues on the urinary, cardiovascular systems, and oral health. It reduces hyperbilirubinemia and uremia ${ }^{9}$. According to Khan and Phyllis ${ }^{10,11}$ studies, this plant extract prevents irritation, spasms in the urinary tract, and it has a diuretic action. The extract of Ammi visnaga $L$., including its pure compounds (khelline and visnagine), induces mechanisms to prevent the deposition of calcium oxalate crystals in the kidneys ${ }^{12}$.

Moreover, the work of Meiouet ${ }^{13}$ showed that the extract of khella fruits could also be used in the treatment of cystine stones since these allowed the complete dissolution of cystine crystals in vitro in six weeks. Ammi visnaga L. butanolic extract tested with DPPH shows an antioxidant activity of $78.7 \%$ at a concentration of $200 \mu \mathrm{g} / \mathrm{mL}$. Other studies by Bencheraiet ${ }^{14}$ and Ashour ${ }^{15}$ proved the antioxidant activity of Ammi visnaga L. extract, and the results revealed by Ammour kenza ${ }^{16}$ demonstrate a robust antioxidant power for hydro-alcoholic extract.

The objective of this work is to carry out a phytochemical study and to assess the antioxidant 
powers of Ammi visnaga L. using the free radical trapping method DPPH.

In this context, this study is concerned with the phenolic extracts of Ammi visnaga L., which is an aromatic and medicinal plant from the Apiaceae family, to assess their antioxidant activities.

\section{Materials and Methods}

\subsection{Plant material}

The aerial part (umbels) of Ammi visnaga L. was harvested in the city of Meknès on the road leading to Sidi Kacem (Meknès-Fès region) in June 2017 (in the Moroccan province of the Middle Atlas). This plant grows in this location in a natural state. The plant material consists mainly of umbels at the time of fruiting. They were dried in the shade and then reduced to a fine powder to carry out phytochemical screening. It was identified at the Rabat Scientific Institute.

\subsection{Phytochemical Screening}

In order to identify the major families of secondary metabolites contained in the plant extract, phytochemical screening was carried out, which was based either on the formation of insoluble complexes using precipitation reactions or on the formation of colored complexes using staining reactions. According to the experimental protocols of Bruneton ${ }^{17}$ and Sofowora ${ }^{18}$, characterization tests of different chemical groups were accomplished by decoction, infusion, and maceration.

The search for alkaloids was carried out by precipitation reactions with general reagents (Mayer and Dragendorff), while the reaction with $2 \%$ ferric perchloride was used to detect polyphenols. The flavonoid polyphenols were detected using the cyanidin reaction, while the Stiasny reaction was used for the detection of gallic and catechic tannins. The confirmation of the non-existence of the saponosides was carried out by measuring the foam index. At the same time, the reaction of Liebermann Buchard made it possible to detect the sterols and the triterpenes.

\subsection{Extraction and fractionation of Ammi visnaga $L$. polyphenols}

\subsubsection{Extraction by maceration}

Thirty grams of dried Ammi visnaga L. powder, aqueous methanol (70\%), and aqueous acetone (70\%) are introduced into an Erlenmeyer flask. The extraction is carried out by maceration for 24 hours at room temperature. The obtained filtrate is kept, and the marc is extracted under the same conditions until a total of three macerations are reached. The final volume (cumulative filtrates) is concentrated in a rotary evaporator.

A second extraction of polyphenols is carried out under the same conditions with distilled water as a solvent from an identical mass of pre-extracted drug.

\subsubsection{Extraction by Soxhlet}

A quantity of 30 grams of dried Ammi visnaga $L$. powder from a dry pulverized sample was extracted within aqueous methanol (70\%) and aqueous acetone (70\%) for 6 h using the Soxhlet method. A total of five cycles is necessary for the depletion of the plant material. After filtration, the solvent is removed from the filtrate by evaporation under vacuum. The residue obtained constitutes the extract of crude polyphenols.

Another extraction by Soxhlet is made using water as solvent under the same conditions with an identical mass of pre-extracted vegetable drug.

\subsubsection{Fractionation of Ammi visnaga $L$. polyphenols}

The fractionation of Ammi visnaga L. polyphenols (crude extracts obtained above) was carried out according to the Protocol of Bruneton ${ }^{19}$ with slight modifications. It is based on the degree of solubility of polyphenols in organic solvents. The fractionation of the extracts is conducted using ethyl acetate, and nbutanol. In addition to the hydro-methanolic or hydroacetonic crude extract (F0), three other fractions are obtained: the ethyl acetate fraction $(\mathrm{F} 1)$, the $\mathrm{n}$ butanolic fraction (F2) and the aqueous fraction (F3). Then all fractions were dried by using a rotary evaporator at $60^{\circ} \mathrm{C}$ and preserved at $4^{\circ} \mathrm{C}$.

\subsection{Determination of the total polyphenols content}

The determination of total polyphenols was carried out using the Folin-Ciocalteu reagent, as described in 1965 Singleton ${ }^{20}$.

A volume of $40 \mu \mathrm{L}$ of each extract (F0, F1, F2, and F3) is introduced into a $100 \mathrm{~mL}$ volumetric flask. Then $1.5 \mathrm{~mL}$ of the Folin-Ciocalteu reagent 10 times diluted, and $1.5 \mathrm{~mL}$ of $7.5 \%$ sodium carbonate is added. The flasks are shaken and completed with distilled water, then stored for 30 minutes at room temperature. The reading is performed against a blank using a spectrophotometer at $760 \mathrm{~nm}$. A calibration curve is carried out in parallel under the same operating conditions using gallic acid as a positive control.

Concentrations of phenolic compounds of each extract were calculated from the equation of the regression of the calibration range with gallic acid $\left.(y=0,095 \times+0,003) R^{2}=0,998\right)$. The obtained results are expressed in milligrams $(\mathrm{mg})$ equivalent of gallic acid per gram of dry plant (mg GAE / g).

\subsection{Chromatographic analysis of the polyphenolic extracts of Ammi visnaga $L$. using high-pressure liquid chromatography coupled to mass spectrometry (HPLC/UV-ESI-MS)}

The chromatographic analysis of the polyphenols in various extracts of Ammi visnaga L. it was is carried out by HPLC equipped with a UV/Vis detector. The column used is of reverse phase $\mathrm{C} 18$ type. The mobile phase for the elution of molecules is a mixture of 
solvents formed from acetonitrile, and a solution of phosphoric acid with $(0.05 \mathrm{M})$. The solvent gradient in this experiment is as follows: $2 \%$ acetonitrile (isocratic) 0-3 $\mathrm{min}, 2-30 \%$ acetonitrile in phosphoric acid (linear gradient) 3-19 min, 30-80\% acetonitrile in phosphoric acid (linear gradient) 19-23 min, 80\% acetonitrile in phosphoric acid (isocratic) 23-28 min, $80-2 \%$ acetonitrile in phosphoric acid (linear gradient) 28-32 min, and 2\% acetonitrile (isocratic) 32-40 min. The flow rate is $1.5 \mathrm{~mL} / \mathrm{min}$. The injection volume is $20 \mu \mathrm{L}$. Detection in the U.V. is done by scanning in the wavelength range: $200-400 \mathrm{~nm}$ and then at three acquisition wavelengths $280 \mathrm{~nm}, 349 \mathrm{~nm}$, and $254 \mathrm{~nm}$. Electrospray is the method used to ionize molecules during mass spectrometry. The standard polyphenols used are gallic acid, ellagic acid, tannic acid, quercetin, and coumarin. The analysis of the eluted compounds is carried out by comparing the retention times of the various peaks of the extracts $70 \%$ hydro-acetone macerate, and aqueous macerate, the two extracts are obtained by reflux at Soxhlet in $70 \%$ acetone and in water, with those of the peaks corresponding to the standards, then by the analysis of the mass spectra of the eluted molecules.

\subsection{Antioxidant activity}

To evaluate the antioxidant property, we used the DPPH method, the solution of DPPH (1,1 -diphenyldi-picrylhydrazyl) at $6.10^{-5} \mathrm{M}$ is obtained by dissolving $2.4 \mathrm{mg}$ of the DPPH powder in $100 \mathrm{~mL}$ ethanol. The extract samples were prepared by dissolution in ethanol at a rate of $1.6 \mathrm{mg} / \mathrm{mL}$.
The test is carried out by mixing a volume of $2.8 \mathrm{~mL}$ of the previous DPPH solution with $200 \mu \mathrm{L}$ of the ethyl acetate extract from our samples or of the standard (Ascorbic acid) at different concentrations (from 0 to $200 \mu \mathrm{g} / \mathrm{mL}$ ). After 30 minutes of incubation in the dark at room temperature, then the absorbance is read at $515 \mathrm{~nm}$ against a blank, which contains only ethanol. The positive control consists of DPPH without extract, radical scavenging activity against DPPH was expressed as a percentage of inhibition, and this was calculated according to the following formula:

$A A \%=\frac{\mathrm{A}_{\text {control }}-\mathrm{A}_{\text {sample }}}{\mathrm{A}_{\text {control }}} \times 100$

A.A. \%: Percentage of the antioxidant activity.

A control: Absorbance of the DPPH solution (Absorbance of the control)

A Sample: Absorbance of the sample to be tested in the presence of DPPH (Absorbance of the sample)

The graph representing the variation in absorbance as a function of the concentrations of the extracts made it possible to determine $\mathrm{IC}_{50}$ (concentration corresponding to the loss of $50 \%$ of the activity of the free radicals).

A dose-response curve was plotted, from which the $\mathrm{IC}_{50}$ value was extrapolated, using the percentage of inhibition values. The antioxidant activity was expressed as $\mathrm{IC}_{50}$ value, which was the concentration $(\mathrm{mg} / \mathrm{mL})$ that inhibited the DPPH radicals by $50 \%$.

Table 1. Results of the characterization reactions of the different chemical groups in the umbels of Ammi visnaga $L$.

\begin{tabular}{|c|c|c|}
\hline Chemical groups & Colors / precipitate & Results \\
\hline Alkaloids & $\begin{array}{l}\text { Dragoendorff reagent: precipitated } \\
\text { reagent Mayer: precipitated }\end{array}$ & $\begin{array}{l}++ \\
++\end{array}$ \\
\hline $\begin{array}{l}\text { Tannins: } \\
\text {-Gallics } \\
\text {-Catechics }\end{array}$ & $\begin{array}{l}\text { Blackish brown } \\
\text { Absence of precipitate } \\
\text { Absence of precipitate }\end{array}$ & - \\
\hline $\begin{array}{l}\text { Flavonoids: } \\
\text {-Anthocyanin } \\
\text {-Flavones } \\
\text {-Leucoanthocyane }\end{array}$ & $\begin{array}{l}\text { Greenish } \\
\text { Orange pink } \\
\text { dark Green }\end{array}$ & $\begin{array}{l}- \\
+ \\
-\end{array}$ \\
\hline $\begin{array}{l}\text {-Antraquinones free } \\
\text {-Combined antraquinones (Genin c- } \\
\text { heterosides) }\end{array}$ & $\begin{array}{l}\text { Green } \\
\text { Orange }\end{array}$ & $\begin{array}{l}- \\
-\end{array}$ \\
\hline -Sterols and triterpenes & Green supernatant with a brownish-red ring & + \\
\hline -Oses and holosides & Red & + \\
\hline -Mucilage & Whitish floc & + \\
\hline
\end{tabular}

$(++)$ : abundance; $(+)$ presence; $(-)$ : absence

\section{Results and Discussion}

\subsection{Phytochemical screening}

The phytochemical screening results are presented in Table 1; their analysis showed that the umbels of
Ammi visnaga $L$. contain alkaloids, flavonoids, sterols, triterpenes, and a small proportion of mucilage. Gallic and catechic tannins, oses and holosides, anthracene derivatives, free 
anthraquinones, combined anthraquinones, genin cheterosides, anthocyanin, and leucoanthocyanin tests were negative. These results agree with those of Sabry et al. (2014) ${ }^{20}$ has identified six (6) compounds of alkaloid types in the methanolic extract of the plant originating in Egypt.

These results were confirmed by numerous academic studies such as those of Soro et al., (2015) ${ }^{21}$, A. Jaradat et al., (2015) ${ }^{22}$ and Zoubi et al., ${ }^{23}$ (2016).

\subsection{Determination of the total polyphenols} content

The polyphenols compounds presented in the crude and fractioned extracts ( $\left.\mathrm{F}_{0}, \mathrm{~F}_{1}, \mathrm{~F}_{2}, \mathrm{~F}_{3}\right)$ were expressed as $\mathrm{mg}$ of gallic acid equivalents per gram extract ( $\mathrm{mg}$ GAE/g).

The contents of total polyphenols obtained by the two extraction methods are presented in Figure 1. It turns out from the analysis of all the obtained results that the polyphenol content of Ammi visnaga L. extracts varies according to the polarity of the used solvent and the extraction temperature. Besides, the extracts obtained by the Soxhlet method are the richest in total phenols compared to those obtained by the maceration method. The content of polyphenols in the ethyl acetate fraction $F_{1}$ obtained by Soxhlet registers the highest value $72.36 \mathrm{mg}$ GAE/g against $23.67 \mathrm{mg}$ GAE/g obtained by maceration.

These results reveal that the extract of the acetate ethyl fraction has a high content of total phenols compared to the other fractions. In addition, the extraction by Soxhlet in the presence of the hydro-methanolic and hydro-acetonic mixture can be considered as the best method for polyphenols extraction.

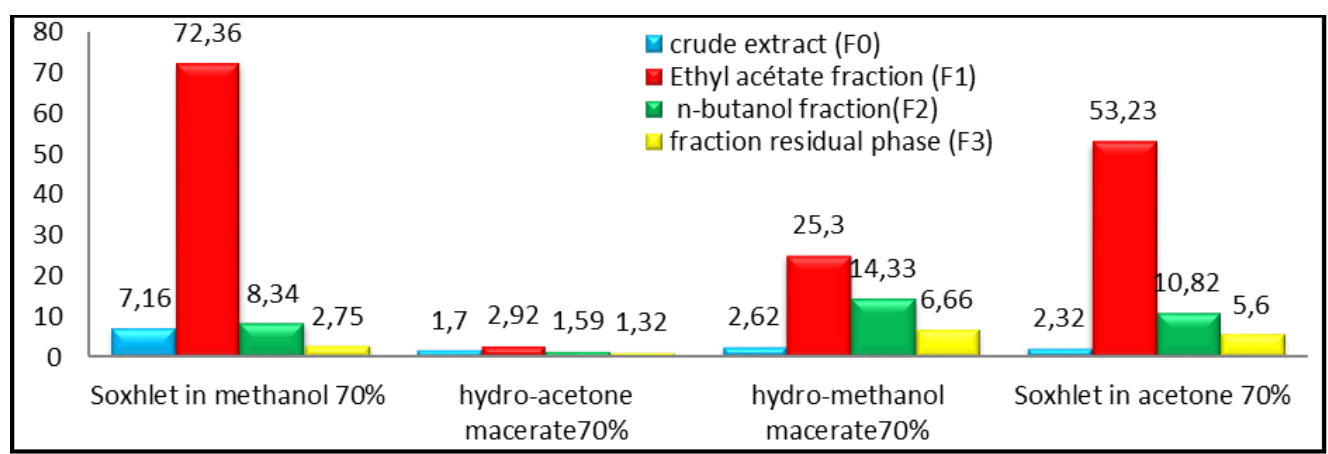

Figure 1. Polyphenol contents of Ammi visnaga Fractions expressed in milligrams of Gallic acid equivalents per gram of dry plant (mg GAT/g)

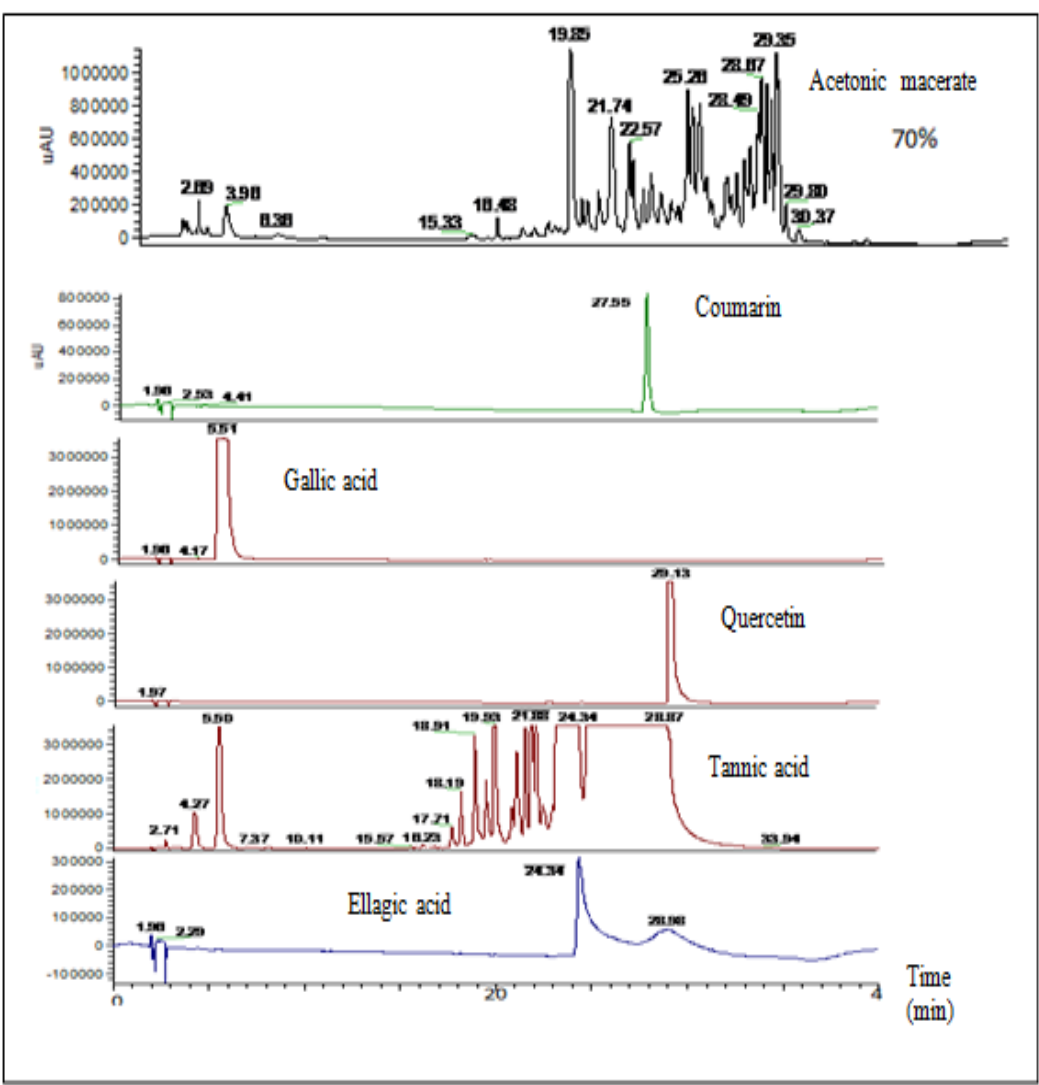

Figure 2. The chromatogram of Ammi visnaga L. extract acetone macerate compared to the chromatograms of reference 
Table 2. List of the compounds identified by mass spectrometry in the polyphenol of Ammi visnaga L. extract acetone macerate.

\begin{tabular}{|c|c|c|c|c|}
\hline No & Compounds & Formulas & Masses & Ions m/z \\
\hline 1 & Rhamnetin & $\mathrm{C} 16 \mathrm{H} 12 \mathrm{O} 7$ & 316 & $317[\mathrm{M}+\mathrm{H}]+$ \\
\hline 2 & Rhamnetin glucoside & $\mathrm{C} 22 \mathrm{H} 24 \mathrm{O} 12$ & 478 & $479[\mathrm{M}+\mathrm{H}]+$ \\
\hline 3 & Rhaminosinrutinoside & $\mathrm{C} 28 \mathrm{H} 32 \mathrm{O} 16$ & 624 & $625[\mathrm{M}+\mathrm{H}]+$ \\
\hline 4 & Kampferolrhamnoside & $\mathrm{C} 21 \mathrm{H} 20 \mathrm{O} 10$ & 432 & $433[\mathrm{M}+\mathrm{H}]+$ \\
\hline 5 & Biochanin A & $\mathrm{C} 16 \mathrm{H} 12 \mathrm{O} 5$ & 284 & $317[\mathrm{M}+\mathrm{Na}]+$ \\
\hline 6 & Biochanin A glucoside & $\mathrm{C} 22 \mathrm{H} 22 \mathrm{O} 10$ & 446 & $469[\mathrm{M}+\mathrm{Na}]+$ \\
\hline 7 & Khellol & $\mathrm{C} 13 \mathrm{H} 10 \mathrm{O} 5$ & 246 & $247[\mathrm{M}+\mathrm{H}]+$ \\
\hline 8 & Khellinin & $\mathrm{C} 19 \mathrm{H} 20 \mathrm{O} 10$ & 408 & $409[\mathrm{M}+\mathrm{H}]+$ \\
\hline 9 & Quercetin & $\mathrm{C} 15 \mathrm{H} 10 \mathrm{O} 7$ & 302 & $303[\mathrm{M}+\mathrm{H}]+$ \\
\hline 10 & Ammiol & $\mathrm{C} 14 \mathrm{H} 12 \mathrm{O} 6$ & 276 & $277[\mathrm{M}+\mathrm{H}]+$ \\
\hline 11 & Ammiol glucoside & $\mathrm{C} 20 \mathrm{H} 22 \mathrm{O} 11$ & 438 & $439[\mathrm{M}+\mathrm{H}]+$ \\
\hline 12 & Kampferol & $\mathrm{C} 15 \mathrm{H} 10 \mathrm{O} 6$ & 286 & $287[\mathrm{M}+\mathrm{H}]+$ \\
\hline 13 & Kaempferol glucoside & $\mathrm{C} 21 \mathrm{H} 20 \mathrm{O} 11$ & 448 & $449[\mathrm{M}+\mathrm{H}]+$ \\
\hline 14 & Kampferolrutinoside & $\mathrm{C} 27 \mathrm{H} 30 \mathrm{O} 15$ & 594 & $595[\mathrm{M}+\mathrm{H}]+$ \\
\hline 15 & Rhamnazine & $\mathrm{C} 17 \mathrm{H} 14 \mathrm{O} 7$ & 330 & $331[\mathrm{M}+\mathrm{H}]+$ \\
\hline 16 & Rhamnazine glucoside & $\mathrm{C} 23 \mathrm{H} 24 \mathrm{O} 12$ & 492 & $493[\mathrm{M}+\mathrm{H}]+$ \\
\hline 17 & Apiine & $\mathrm{C} 26 \mathrm{H} 28 \mathrm{O} 14$ & 564 & $565[\mathrm{M}+\mathrm{H}]+$ \\
\hline 18 & Chrysoeriol & $\mathrm{C} 16 \mathrm{H} 12 \mathrm{O} 6$ & 300 & $301[\mathrm{M}+\mathrm{H}]+$ \\
\hline 19 & Khrysoerol glucoside & $\mathrm{C} 22 \mathrm{H} 22 \mathrm{O} 11$ & 462 & $463[\mathrm{M}+\mathrm{H}]+$ \\
\hline 20 & Khelline & $\mathrm{C} 14 \mathrm{H} 12 \mathrm{O} 5$ & 260 & $261[\mathrm{M}+\mathrm{H}]+$ \\
\hline 21 & visnagine & $\mathrm{C} 13 \mathrm{H} 10 \mathrm{O} 4$ & 230 & $231[\mathrm{M}+\mathrm{H}]+$ \\
\hline
\end{tabular}

3.3.1.2. Identification of polyphenols using water as an extraction solvent

Figure 3 represents the chromatogram of the Ammi.visnaga L. extract obtained by maceration with water as extraction solvent (aqueous macerate). From the analysis of this chromatogram, we deduce the presence of coumarin and flavonoids as well as the absence of a small quantity of gallic tannins. The identified molecules by the mass spectra analysis are presented in Table 3.

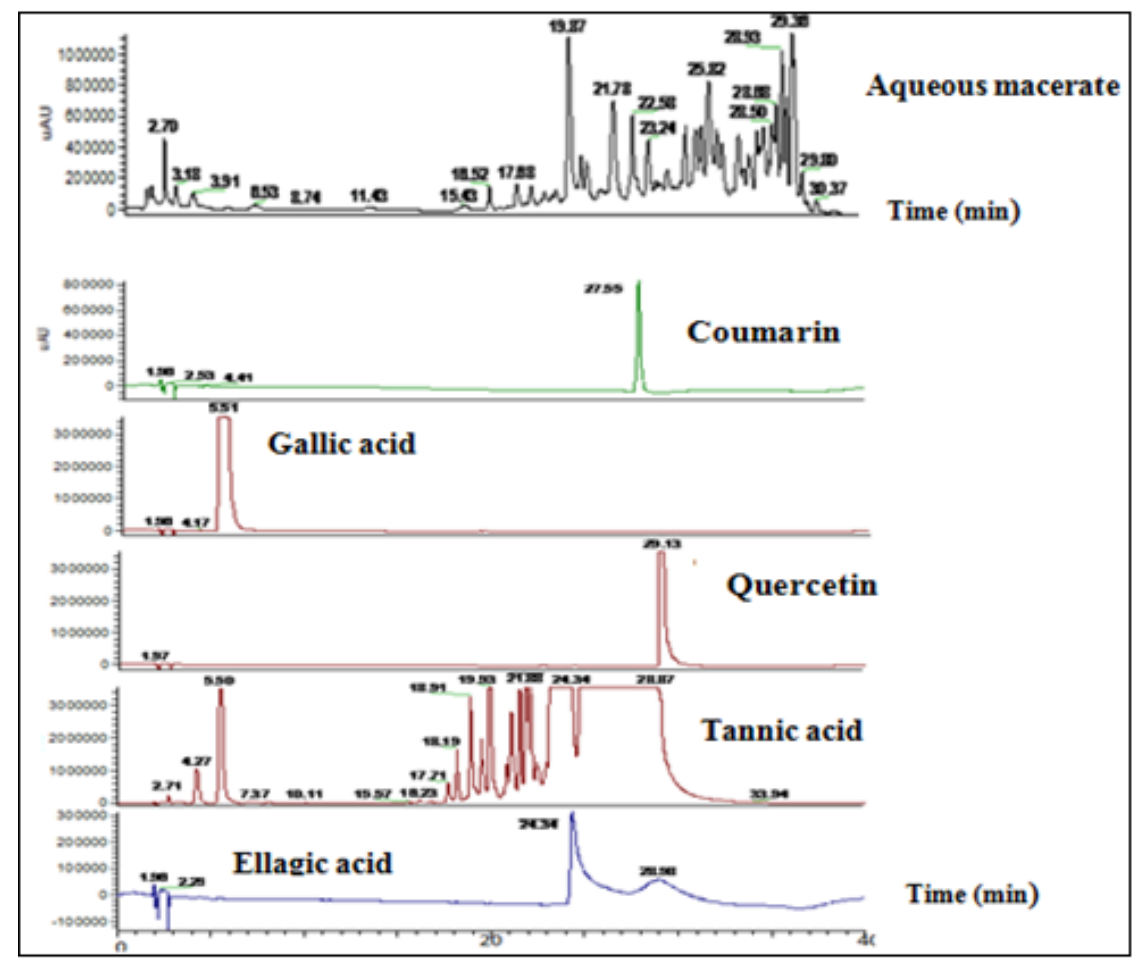

Figure 3. The chromatogram of the Ammi visnaga $L$. extract acetone macerate compared to the chromatograms of reference 
Table 3. List of compounds identified by mass spectrometry in the Ammi visnaga L. extract of polyphenols obtained by maceration in the water.

\begin{tabular}{|c|c|c|c|c|}
\hline No & Compounds & Formulas & Masses & Ions $\mathbf{m} / \mathbf{z}$ \\
\hline 1 & Biochanin A glucoside & $\mathrm{C} 22 \mathrm{H} 22 \mathrm{O} 10$ & 446 & $447[\mathrm{M}+\mathrm{H}]^{+}$ \\
\hline 2 & Khellol & C13H10O5 & 246 & $246[\mathrm{M}+\mathrm{H}]+$ \\
\hline 3 & Khellinin & $\mathrm{C} 19 \mathrm{H} 20 \mathrm{O} 10$ & 408 & $409[\mathrm{M}+\mathrm{H}]+$ \\
\hline 4 & Quercetin & C15H10O7 & 302 & $303[\mathrm{M}+\mathrm{H}]+$ \\
\hline 5 & Ammiol & C14H12O6 & 276 & $276[\mathrm{M}+\mathrm{H}]+$ \\
\hline 6 & Ammiol glucoside & $\mathrm{C} 20 \mathrm{H} 22 \mathrm{O} 11$ & 438 & $439[\mathrm{M}+\mathrm{H}]+$ \\
\hline 7 & Biochanin A & $\mathrm{C} 16 \mathrm{H} 12 \mathrm{O} 5$ & 284 & $285[\mathrm{M}+\mathrm{H}]+$ \\
\hline 8 & Kaempferol & C15H10O6 & 286 & $287[\mathrm{M}+\mathrm{H}]+$ \\
\hline 9 & Rhamnetine & $\mathrm{C} 16 \mathrm{H} 12 \mathrm{O} 7$ & 316 & $317[\mathrm{M}+\mathrm{H}]+$ \\
\hline 10 & Kaempferol glucoside & $\mathrm{C} 21 \mathrm{H} 20 \mathrm{O} 11$ & 448 & $449[\mathrm{M}+\mathrm{H}]+$ \\
\hline 11 & Kampferolrutinoside & C27H30O15 & 594 & $595[\mathrm{M}+\mathrm{H}]+$ \\
\hline 12 & Rhamnetine glucoside & $\mathrm{C} 22 \mathrm{H} 24 \mathrm{O} 12$ & 478 & $479[\mathrm{M}+\mathrm{H}]+$ \\
\hline 13 & Rhamnetinerutinoside & C28H32O16 & 624 & $625[\mathrm{M}+\mathrm{H}]+$ \\
\hline 14 & Rhamnazine glucoside & $\mathrm{C} 23 \mathrm{H} 24 \mathrm{O} 12$ & 494 & $495[\mathrm{M}+\mathrm{H}]+$ \\
\hline 15 & Rhamnazinerutinoside & С29H34O16 & 638 & $639[\mathrm{M}+\mathrm{H}]+$ \\
\hline 16 & Vitaminol & C16H18O5 & 290 & $291[\mathrm{M}+\mathrm{H}]+$ \\
\hline 17 & Vitaminol glucoside & $\mathrm{C} 22 \mathrm{H} 28 \mathrm{O} 10$ & 452 & $453[\mathrm{M}+\mathrm{H}]+$ \\
\hline 18 & Chrysoeriol & C16H12O6 & 300 & $301[\mathrm{M}+\mathrm{H}]+$ \\
\hline 19 & Chrysoerol glucoside & $\mathrm{C} 22 \mathrm{H} 22 \mathrm{O} 11$ & 462 & $463[\mathrm{M}+\mathrm{H}]+$ \\
\hline 20 & Khelline & $\mathrm{C} 14 \mathrm{H} 12 \mathrm{O} 5$ & 260 & $261[\mathrm{M}+\mathrm{H}]+$ \\
\hline 21 & Visnagine & C13H10O4 & 230 & $231[\mathrm{M}+\mathrm{H}]+$ \\
\hline
\end{tabular}

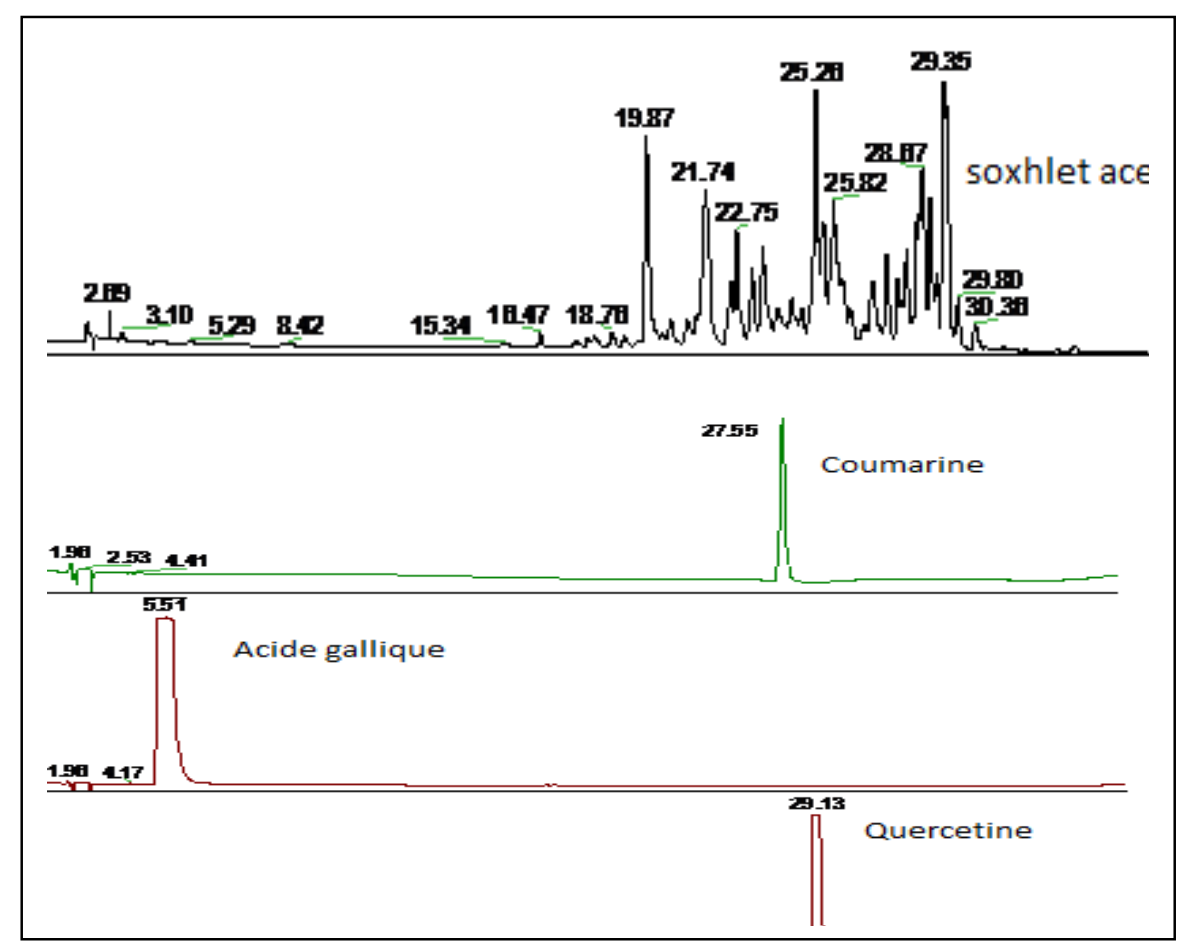

Figure 4. The chromatogram of the Ammi visnaga L. extract obtained by Soxhlet with acetone as extraction solvent compared to the chromatograms of reference 
Table 4. List of compounds identified by mass spectrometry in the Ammi visnaga L. extract of polyphenols obtained by Soxhlet using acetone $70 \%$.

\begin{tabular}{|c|c|c|c|c|}
\hline No. & Compounds & Formulas & The Masses & The ions m/z \\
\hline 1 & Chrysoeriol & C16H12O6 & 300 & $301[\mathrm{M}+\mathrm{H}]+$ \\
\hline 2 & Chrysoeriol glucoside & C22H22O11 & 462 & $463[\mathrm{M}+\mathrm{H}]+$ \\
\hline 3 & Khellol & C13H10O5 & 246 & $247[\mathrm{M}+\mathrm{H}]+$ \\
\hline 4 & Khellinin & $\mathrm{C} 19 \mathrm{H} 20 \mathrm{O} 10$ & 408 & $409[\mathrm{M}+\mathrm{H}]+$ \\
\hline 5 & Quercetin & $\mathrm{C} 15 \mathrm{H} 10 \mathrm{O} 7$ & 302 & $303[\mathrm{M}+\mathrm{H}]+$ \\
\hline 6 & Ammiol & $\mathrm{C} 14 \mathrm{H} 12 \mathrm{O}$ & 276 & $277[\mathrm{M}+\mathrm{H}]+$ \\
\hline 7 & Ammiol glucoside & $\mathrm{C} 20 \mathrm{H} 22 \mathrm{O} 11$ & 438 & $439[\mathrm{M}+\mathrm{H}]+$ \\
\hline 8 & Biochanin A & $\mathrm{C} 16 \mathrm{H} 12 \mathrm{O} 5$ & 284 & $284[\mathrm{M}+\mathrm{H}]+$ \\
\hline 9 & dihydroammiol glucoside & $\mathrm{C} 20 \mathrm{H} 24 \mathrm{O} 11$ & 440 & $441[\mathrm{M}+\mathrm{H}]+$ \\
\hline 10 & Kaempferol & $\mathrm{C} 15 \mathrm{H} 10 \mathrm{O} 6$ & 286 & $287[\mathrm{M}+\mathrm{H}]+$ \\
\hline 11 & Kaempferol glucoside & $\mathrm{C} 21 \mathrm{H} 20 \mathrm{O} 11$ & 448 & $449[\mathrm{M}+\mathrm{H}]+$ \\
\hline 12 & Kampferolrutinoside & $\mathrm{C} 27 \mathrm{H} 30 \mathrm{O} 15$ & 594 & $595[\mathrm{M}+\mathrm{H}]+$ \\
\hline 13 & Rhamnetin & $\mathrm{C} 16 \mathrm{H} 12 \mathrm{O} 7$ & 316 & $317[\mathrm{M}+\mathrm{H}]+$ \\
\hline 14 & Rhamnetin glucoside & $\mathrm{C} 22 \mathrm{H} 24 \mathrm{O} 12$ & 478 & $479[\mathrm{M}+\mathrm{H}]+$ \\
\hline 15 & Rhaminosinrutinoside & $\mathrm{C} 28 \mathrm{H} 32 \mathrm{O} 16$ & 624 & $625[\mathrm{M}+\mathrm{H}]+$ \\
\hline 16 & visaminol & $\mathrm{C} 16 \mathrm{H} 18 \mathrm{O} 5$ & 290 & $291[\mathrm{M}+\mathrm{H}]+$ \\
\hline 17 & Rhamnazine & $\mathrm{C} 17 \mathrm{H} 14 \mathrm{O} 7$ & 330 & $331[\mathrm{M}+\mathrm{H}]+$ \\
\hline 18 & Rhamnazine glucoside & $\mathrm{C} 23 \mathrm{H} 24 \mathrm{O} 12$ & 492 & $493[\mathrm{M}+\mathrm{H}]+$ \\
\hline 19 & Apiine & $\mathrm{C} 26 \mathrm{H} 28 \mathrm{O} 14$ & 564 & $565[\mathrm{M}+\mathrm{H}]+$ \\
\hline 20 & Khelline & $\mathrm{C} 14 \mathrm{H} 12 \mathrm{O} 5$ & 260 & $261[\mathrm{M}+\mathrm{H}]+$ \\
\hline 21 & Visnagine & $\mathrm{C} 13 \mathrm{H} 10 \mathrm{O} 4$ & 230 & $231[\mathrm{M}+\mathrm{H}]+$ \\
\hline
\end{tabular}

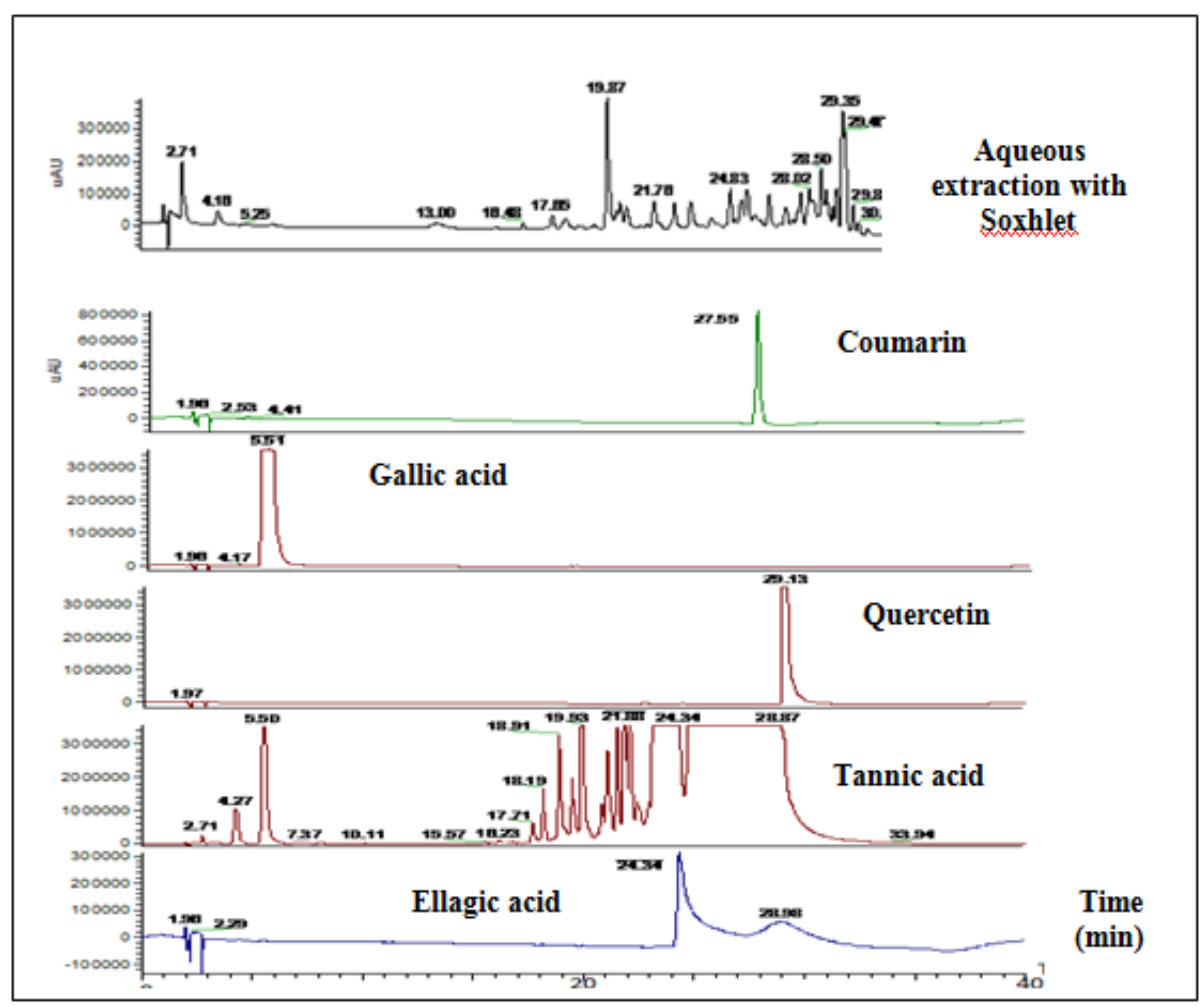

Figure 5. HPLC chromatograms of the polyphenols (coumarin, gallic acid, quercetin, tannic acid, ellagic acid) and Ammi visnaga L. polyphenols obtained by aqueous extraction with Soxhlet 
Table 5. List of compounds identified by mass spectrometry in the Ammi visnaga L. extract obtained by Soxhlet technique.

\begin{tabular}{|c|c|c|c|c|}
\hline No. & Compounds & Formulas & Masses & Ions m/z \\
\hline 1 & Biochanin A & C16H12O5 & 284 & $307[\mathrm{M}+\mathrm{Na}]+$ \\
\hline 2 & Rhamnetin & C16H12O7 & 316 & $317[\mathrm{M}+\mathrm{H}]+$ \\
\hline 3 & Rhamnetin glucoside & C22H24O12 & 478 & $479[\mathrm{M}+\mathrm{H}]+$ \\
\hline 4 & Rhaminosinrutinoside & C28H32O16 & 624 & $625[\mathrm{M}+\mathrm{H}]+$ \\
\hline 5 & Khellol & C13H10O5 & 246 & $246[\mathrm{M}+\mathrm{H}]+$ \\
\hline 6 & Ammiol & $\mathrm{C} 14 \mathrm{H} 12 \mathrm{O} 6$ & 276 & $277[\mathrm{M}+\mathrm{H}]+$ \\
\hline 7 & Apiine & $\mathrm{C} 26 \mathrm{H} 28 \mathrm{O} 14$ & 564 & $564[\mathrm{M}+\mathrm{H}]+$ \\
\hline 8 & Rhamnazine & $\mathrm{C} 17 \mathrm{H} 14 \mathrm{O} 7$ & 330 & $331[\mathrm{M}+\mathrm{H}]+$ \\
\hline 9 & Rhamnazine glucoside & $\mathrm{C} 23 \mathrm{H} 24 \mathrm{O} 12$ & 492 & $493[\mathrm{M}+\mathrm{H}]+$ \\
\hline 10 & Rhamnazinerutinoside & $\mathrm{C} 29 \mathrm{H} 34 \mathrm{O} 16$ & 638 & $639[\mathrm{M}+\mathrm{H}]+$ \\
\hline 11 & Chrysériol & $\mathrm{C} 16 \mathrm{H} 12 \mathrm{O} 6$ & 300 & $301[\mathrm{M}+\mathrm{H}]+$ \\
\hline 12 & Diosmetinerutinoside & $\mathrm{C} 28 \mathrm{H} 32 \mathrm{O} 15$ & 608 & $609[\mathrm{M}+\mathrm{H}]+$ \\
\hline 13 & Apigeninneohesperidoside & $\mathrm{C} 27 \mathrm{H} 30 \mathrm{O} 14$ & 578 & $579[\mathrm{M}+\mathrm{H}]+$ \\
\hline 14 & Khellinin & $\mathrm{C} 19 \mathrm{H} 20 \mathrm{O} 10$ & 408 & $409[\mathrm{M}+\mathrm{H}]+$ \\
\hline 15 & Visnagine & $\mathrm{C} 13 \mathrm{H} 10 \mathrm{O} 4$ & 230 & $231[\mathrm{M}+\mathrm{H}]+$ \\
\hline
\end{tabular}

\subsubsection{Discussion}

The analysis of mass spectra in a positive mode made it possible to identify different molecules from the molecular peaks generated.

Thus, kampferol-rutinoside was identified by its molecular peak at $\mathrm{m} / \mathrm{z}=595[\mathrm{M}+\mathrm{H}]^{+}$, its peak at $\mathrm{m} / \mathrm{z}=449[\mathrm{M}+\mathrm{H}]{ }^{+}$corresponding to kampferolglucoside (after the loss of 'a unit of rhamnose: -146) and its peak $\mathrm{m} / \mathrm{z}=287[\mathrm{M}+\mathrm{H}]{ }^{+}$corresponds to kampferol (following the loss of a unit of glucose: -162).

Similarly, rhamnetin-rutinoside has been identified by its molecular peak at $\mathrm{m} / \mathrm{z}=625[\mathrm{M}+\mathrm{H}]+$, its peak $\mathrm{m} / \mathrm{z}=479[\mathrm{M}+\mathrm{H}]{ }^{+}$corresponding to rhamnetinglucoside (after the loss of a unit of rhamnose: -146) and its peak at $\mathrm{m} / \mathrm{z}=317[\mathrm{M}+\mathrm{H}]{ }^{+}$corresponds to rhamnetin (following the loss of a unit of glucose: -162).

Biochanin A and its glucoside were identified respectively by the presence of the peaks at $\mathrm{m} / \mathrm{z}=307$ $[\mathrm{M}+\mathrm{Na}]+$ and $\mathrm{m} / \mathrm{z}=469[\mathrm{M}+\mathrm{Na}]^{+}$.

Apiine is recognized by its molecular peak $[\mathrm{M}+\mathrm{H}]+$ at $\mathrm{m} / \mathrm{z}=565$ and apigenin neohesperidoside by the peak $[\mathrm{M}+\mathrm{H}]^{+}$at $\mathrm{m} / \mathrm{z}=579$.

Visnagine and khelline are identified by their respective molecular peaks $\mathrm{m} / \mathrm{z}=231$ and $\mathrm{m} / \mathrm{z}=261$ $[\mathrm{M}+\mathrm{H}]^{+}$, khellol and khellinine (its glucoside) are present by their respective molecular peaks $\mathrm{m} / \mathrm{z}=247$ and $\mathrm{m} / \mathrm{z}=409[\mathrm{M}+\mathrm{H}]^{+}$.

Also, the ammiol glucoside is identified by the molecular peak at $\mathrm{m} / \mathrm{z}=439[\mathrm{M}+\mathrm{H}]^{+}$. Its loss of one glucose unit (-162) leads to ammiol at $\mathrm{m} / \mathrm{z}=277$. Chrysoeriol is represented by its peak $\mathrm{m} / \mathrm{z}=301$, likewise its glucoside by the peak at $\mathrm{m} / \mathrm{z}=463$ following the addition of a glucose unit.

The chromatographic study of the four Ammi visnaga $L$. extracts confirms the richness of this species on polyphenols and particularly in flavonoids. We note that the difference in the operating procedures used to obtain the plant extracts did not lead to a significant difference in terms of the chemical composition of these. Indeed, all the extracts were characterized by similar chromatographic spectra and the presence of flavonoids as well as furochromones.

The chromatographic analysis did not identify tannins in the extracts despite their use as standards. Therefore, the mass spectrometry used as a complementary analysis method only generated mass spectra in positive mode for the studied extracts, which made it possible to identify different molecules from the molecular peaks generated.

The polyphenols extraction strengthened the results obtained during the phytochemical screening, which highlight the presence of flavonoids in Ammi visnaga $L$. The most of the identified flavonoids are of the flavonol type such as quercetin, rhamnetin, rhamnazine, kaempferol, and their glucosides. The studies of Bencheraiet ${ }^{14}$ confirm our results, they also identified these molecules, while Abdul-Jalil 24 identified kaempferol and quercetin as compounds of the fruits of Ammi visnaga L.

Khellin, visnagin, khellol, which are furochromones that are specific to Ammi visnaga L., are among the 
other polyphenols that we identified. However, the presence of visnadine, a species-specific coumarin, was not revealed with our procedures.

\subsection{Antioxidant activity}

\subsubsection{Trapping of the free radical DPPH}

The antioxidant activity of Ammi visnaga $L$. extracts is determined by the DPPH free radical reduction method. DPPH is generally the most used substrate for the rapid and direct evaluation of the antioxidant activity of various plant extracts, because of its stability in free radical form and of the simplicity of the analysis. The chemical compound 2,2-diphenyl-1picrylhydrazyle is one of the first free radicals used to study the antioxidant activity relationship of phenolic compounds ${ }^{25}$. It has an unpaired electron on a nitrogen atom. The reduction of this radical is accompanied by its change from the purple, characteristic of the DPPH solution, to yellow (DPPH-H). This change is measurable by spectrophotometry at $515 \mathrm{~nm}$. The reduction capacity is determined by a decrease in absorbance induced by anti-free radicals ${ }^{26-28}$. From the obtained results, the inhibition percentages were calculated using the formula given above.

\subsubsection{Required concentrations to reduce $50 \%$ of DPPH}

The inhibition percentages previously determined to make it possible to calculate the value of $\mathrm{IC}_{50}$ (inhibitor concentration), which represents the required concentration of the extract to reduce $50 \%$ of the free radicals in the reaction medium.

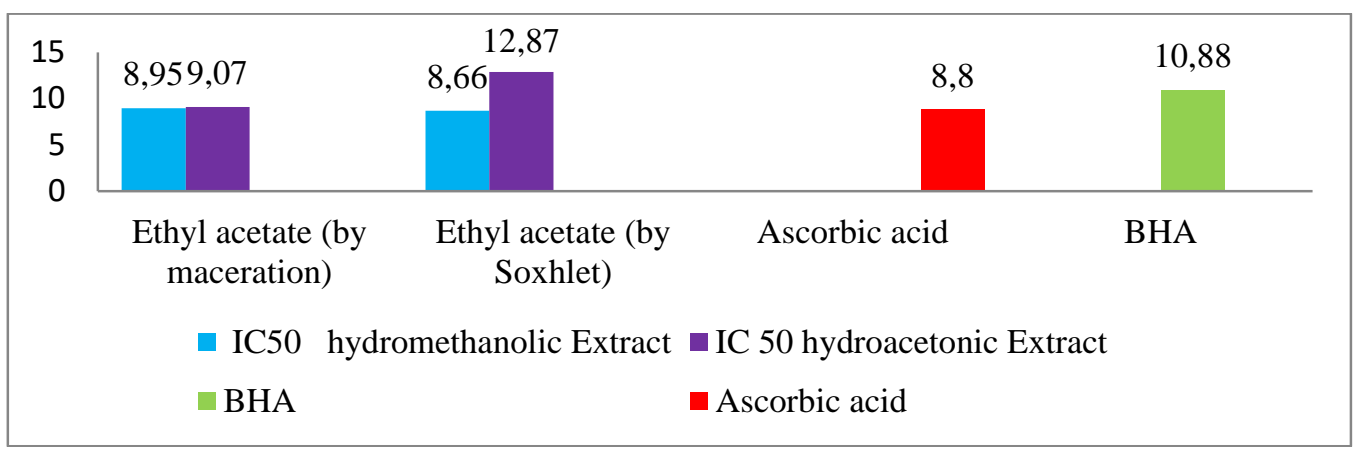

Figure 6. Evaluation of the antioxidant activity by $\mathrm{IC}_{50}$ Values for Ethyl acetate fractions of Ammi visnaga L. various extracts analyzed in comparison with two antioxidant reference substances

The ethyl acetate fraction of hydracetonic extract by Soxhlet revealed the strongest anti-free radical activity $\left(\mathrm{IC}_{50}=12.875 \mathrm{ug} / \mathrm{ml}\right)$ followed by the ethyl acetate fraction of hydromethanolic extract by maceration, with an $\mathrm{IC}_{50}$ approximately $10.88 \mathrm{ug} / \mathrm{ml}$ compared to BHA and ascorbic acid $\left(\mathrm{IC}_{50}=8.8 \mathrm{ug} / \mathrm{ml}\right)$. The difference in the antioxidant activity between the extracts depends mostly on the total phenolic flavonoids and other contents of aromatic compounds present.

The extraction solvent has an effect on the IC50 value from one extract to another ${ }^{29}$, and the treated part of the plant material, as well as the extraction method and the reference, used.

\section{Conclusion}

This phytochemical study shows that Ammi visnaga $L$. is an aromatic and medicinal plant that is rich in molecules with therapeutic potential. In addition, to the molecules such as visnagine, khelline which characterize this plant species, several other molecules were revealed such as mucilages, triterpenes, sterols, alkaloids, and polyphenols. The study of the antioxidant activity of Ammi visnaga $L$. extracts using the DPPH free radical reduction method showed that both methanolic and acetonic extracts have strong antioxidant activities.
The chromatographic analysis of the extracts of Ammi visnaga $L$. using high-pressure liquid chromatography coupled to mass spectrometry (HPLC/UV-ESI-MS) confirmed the richness of this species in polyphenols especially by the identification of kaempferol, rhamnetin, biochanin A, ammiol, etc. These molecules belong to flavones, flavonols, and furochromones, they are also identified in the form of genin and heteroside.

The results of this study proved that Ammi visnaga $L$. is a very interesting plant, which motivates us to carry out a more in-depth study of its activities as well as its role in the therapeutic field.

\section{References}

1- N. M. Yasin, M. Abou-Taleb, Antioxidant and antimicrobial effects of marjoram and thyme in coated refrigerated semi fried mullet fish fillets, World J. Dairy Food Sci., 2007, 2, 1-9.

2- A. Keddad, A. Baaliouamer, M. Hazzit, Chemical Composition and Antioxidant Activity of Essential Oils from Umbels of Algerian Ammi visnaga (L.), J. Essent. Oil Bear. Plants, 2016, 19, 1243-1250.

3- A. E. Al-Snafi, Chemical constituents and pharmacological activities of ammi majus and Ammi visnaga. A review, Int. J. Pharm \& Ind. Res., 2013, 3, 257-265. 
4- P. A. Balch, Prescription for herbal healing, Penguin, 2002.

5- M. W. Quimby, Ammi visnaga L. Lam. A Medicinal Plant, Econ. Bot., 1953, 89-92.

6- C. Bohuon, C. Monneret, C. Monneret, Fabuleux hasards : histoire de la découverte de médicaments, éditions EDP SCIENCES, 2009.

7- B. Boullard, Dictionnaire, plantes médicinales du monde: croyance et réalité, edition ESTEM : Paris, 2001.

8- M. Hmamouchi, Les plantes médicinales et aromatiques marocaines : utilisation, biologie, écologie, chimie, pharmacologie, toxicologie, lexiques, $2^{\text {ème }}$ édition, 2001.

9- N. Khalil, M. Bishr, S. Desouky, O. Salama, Ammi Visnaga L., a Potential Medicinal Plant: A Review, Molecules, 2020, 25, 301.

10-Z. Khan, A. Assiri, H. Al-Afghani, T. Maghrabi, Inhibition of oxalate nephrolithiasis with Ammi visnaga L.(Al-Khillah), International urology and nephrology, 2001, 33, 605-608.

11-B. Phyllis, Prescription for Herbal Healing, $2^{\text {nd }}$ edition: An Easy-to-Use A-to-Z Reference to Hundreds of Common Disorders and Their Herbal Remedies Paperback Published by the Penguin Group, 2002.

12-P. Vanachayangkul, N. Chow, S. R. Khan, V. Butterweck, Prevention of renal crystal deposition by year extract of Ammi visnaga L.L. and its constituents and visnagin in hyperoxaluric rats, Urological Research, 2011, 39, 183-195.

13-F. Meiouet, S. El Kabbaj, M. Daudon, In vitro study of the activity litholytique of four medicinal plants vis-a-vis the urinary calculations of cystine, Progress in urology, 2011, 21, 40-47.

14-R. Bencheraiet, H. Kherrab, A. Kabouche, Z. Kabouche, M. Jay, The flavonols and antioxidant activity of Ammi visnaga $L$. (Apiaceae). Records of natural products, 2011, 5, 52-55.

15-A. Ashour, S, El-Sharkawy, M. Amer, F. Abdel Bar, A. Mera, T. Nagata, R. Kondo, K. Shimizu, Biotransformation of Khellin to Khellol by and the Evaluation of their Biological Activities, The Open Bioactive Compounds Journal, 2013, 4, $1-3$.

16-K. Ammor, B. Dalila, J. Sanae, A. Chaqroune, F. M. Fatima, Total Polyphenol Content and Antioxidant Power of Ammi visnaga L. from Morocco, Der Pharma Chemica, 2017, 9, 73-78.

17-J. Bruneton, Pharmacognosie, Phytochimie et plantes médicinales : Technique et Documentation, $4{ }^{\text {ème }}$ Edition, 2009, 279-281.

18-A. Sofowora, Medicinal plants and traditional medicine in Africa; edition John Wiley and Its; Chichester: New York, 1982, 256.
19-V. L. Singleton, J. A. Rossi, colorimetry of total phenolics with phosphomolybdicphosphotungstic acid reagents, American Journal of Technology and viticulture, 1965, 16, 144-153.

20-A. Sabry, A. El-Said, S. El-Zayat, F. AbdelMotaal, T. Magraby, Fungal contamination of Ammi visnaga seeds, antimicrobial activity of the plant seeds secondary metabolites and detection of alkaloids and non-alkaloids compounds, International Journal of Current Microbiology and Applied Sciences, 2014, 3, 901-914.

21-K. N. Soro, L. Sabri, S. Amalich, Y. Khabbal, T. Zaïr, Chemical composition of Moroccan Ammi visnaga L. (Lam.) and antibacterial activity of its essential oil against extended-spectrum beta-lactamase-producing and not producing bacteria, Phytothérapie. 2015, 13, 168-175.

22- N. A. Jaradat, M. Abu Al Hasan, M. Al-Masri, R. I. Speih, M. A. Johari, M. A. Awad, Phytochemical Screening and In-vitro Evaluation of Antioxidant and Antimicrobial Activities of the Entire Khella Plant (Ammi visnaga. L.) A member of Palestinian Flora, Int. J.

Pharmacognosy and Phytochem. Res, 2015, 7, 137-143.

23-Y. Ez Zoubi, F. El-Akhal, A. Farah, K. Taghzouti, A. El Ouali Lalami, Phytochemical Screening and Larvicidal Activity of Moroccan Ammi visnaga L.Against Larvae West Nile Vector Mosquito Culex pipiens (Diptera: Culicidae), Int. J. Pharmacognosy and Phytochem. Res, 2016, 8, 1684-1688.

24-T. Abdul-Jalil, K. Saour,

A. Nasser, Phytochemical Study of some Flavonoids Completing present in the Fruits of Two Ammi L. Species wildly grown in Iraq, Iraqi J Pharm Sci, 2010, 19, 48-57.

25-W. Brand-Williams, M. E. Cuvelier, C. Berset, Use of a free radical method to evaluate antioxidant activity, LWT - Food Sci. Technol, 1995, 28, 25-30.

26-A. Prakash, Analytical Progress Medallion Laboratories Antioxidant Activity what are antioxidants, 2001, 19(2).

27- S. Karouche, S. Khaldi, A. Benbott, Phytochemical, Free Radical Scavenging and Antimicrobial Activities of the Maize Stigmas, Collected of Ain Mlila (East Algeria), World J Environ Biosci., 2018, 7, 35-40.

28-L. Majhenic, M. Skerget, Z. Knez, Antioxidant and antimicrobial activity of guarana seed extracts, Food Chem, 2007,104, 1258-1268.

29-K. Zhou, L. Yu, Effects of extraction solvent on wheat bran antioxidant activity estimation, LWT, Food Sci. Tech, 2004, 37, 717-721. 